to the science of oceanography. In the absence of Dr. Hjort, the medal was received by the Norwegian Minister, Mr. Bryn.

The Comstock prize of $I_{500}$ dollars to Prof. Robert A. Millikan, of Chicago, for his demonstrations of the existence of electric atoms in elements and of the equality of the electrical charge of positive and negative ions in ionised gases, and his additions to the knowledge of the molecular constitution and kinetic phenomena of gases.

A business meeting was held on the morning of April 24, when the following officers and new members and foreign associates were elected: President, William $\mathrm{H}$. Welch; Vice-President, Charles D. Walcott; Foreign Secretary, George E. Hale; Home Secretary, Arthur L. Day; Treasurer, Whitman Cross. New Members: Henry A. Bumstead, Gilbert N. Lewis, Louis V. Pirsson, Erwin F. Smith, Leonard E. Dickson, Lafayette B. Mendel, Edward B. Rosa, Ross G. Harrison, George H. Parker, Armin O. Leuschner. New Foreign Associates: Arthur Schustcr, Theodor Boveri, William Crookes, Gaston Darboux, Henri Deslandres, Albert Heim, Albrecht Kossel, Karl Friedrich Küstner, Johannes D. van der Waals, August Weismann, Max F. J. C. Wolf.

On the afternoon of April 24 an excursion was made to Mount Vernon on the U.S.S. Mayflower, which had been placed at the disposal of the academy and its guests by the Secretary of the Navy. In the evening a banquet was held in the New Willard Hotel, at which speeches were made by Vice-President Marshall, the Right Hon. James Bryce, President Remsen, Dr. S. Weir Mitchell, Senator T. E. Burton, of Ohio, and Dr. W. W. Keen, President of the American Philosophical Society.

To mark the anniversary, the academy published a history of its first half-century in a handsome volume of some 400 pages. It includes an account of the founding of the academy, its annals, biographical sketches of the incorporators, and a chapter on the work of the academy as the scientific adviser of the Government, together with appendices, among which is a list of publications.

\section{SCALES OF FISH AS TESTS OF AGE.}

THE general principle that the age of a fish may be determined by a study of the markings on the scale has now been generally accepted for many fishes, especially for the Gadoids, Clupeoids, and Salmonidæ. It has been maintained, especially by Norwegian naturalists, that the principle may be carried still further, and that from a measurement of the portions of the scale representing the growth of successive years the length of the fish at the end of each year of its life may be calculated. If this proved to be true, the average annual growth rate of fishes could be determined by the examination of comparatively small samples of fish, since each of the older fishes would give values for a number of years.

That the use of the method in this way must NO. 2272, VOL. 9I] be undertaken only with great caution is clearly shown in a paper by Miss Rosa M. Lee, published by the International Council for the Study of the Sea (Publications de Circonstance, No. 63), entitled "An Investigation into the Methods of Growth Determination in Fishes." By an acute and penetrating analysis of the measurements of scales from herring, haddock, and trout, Miss Lee shows that if the lengths of the fish at the end of each year are calculated from the lengths of the annual rings on the scale, measured from the centre of the scale along its major axis, the figures obtained appear to indicate a change in the growth rate of such a nature that the younger fishes attained a greater size at any given age than was attained by older fishes at the same given age. Thus whereas in a sample of herrings the four-year-old class gave an average calculated length of $25^{\circ} 8 \mathrm{~cm}$. at the end of the third year, the ten-year-old class gave an average calculated length of only $2 \mathrm{I}^{\prime} 3 \mathrm{~cm}$. at the end of their third year.

Various hypotheses are put forward to account for this phenomenon, of which the most probab!e seems to be either that it is due to an actual shrinkage during the later life of the fish of the portion of the scale already laid down, or that in the samples of fish examined there has been a segregation according to size of such a character that only the larger sizes of the earlier age groups are present. The subject is clearly one which must be further investigated before certain conclusions as to age can be arrived at from the study of fish scales.

\section{THE ROYAL SOCIETY CONVERSAZIONE.}

THE annual May conversazione of the Royal Society was held in the rooms of the society at Burlington House on Wednesday, May 7 . During the evening lantern demonstrations were given by Mr. Leonard Bairstow illustrating cases of eddying fluid motion of interest in aëronautical research, and by Dr. A. Smith Woodward on the discovery of a palæolithic human skull and mandible at Piltdown, Fletching, Sussex. Many objects and instruments illustrating recent scientific methods and results were exhibited, and most of them are described in the subjoined summaries from the official catalogue. Exhibits referring to related branches of science have, so far as possible, been grouped together.

Prof. J. T. Morris: The electrical measurement of wind velocity, as applied to the distribution round a circular rod in an air current. In the air current is fixed a Wheatstone bridge made with alternate arms of platinum and manganin. At normal temperature this bridge is out of balance. It is supplied with either $(a)$ a constant voltage, when a millivoltmeter in place of the usual galvanometer gives indications depending on the wind velocity; or $(b)$ a current which can be varied so as to bring the bridge into balance for any velocity; the square of the watts used in the bridge wires is then proportional to the wind velocity subject to a small correction. It is unnecessary to know the direction of the wind before a measurement can be made. Mr. $M$. 
O'Gorman: Instruments for aëronautical work, and research on aëroplane stability. (I) Ripograph: to record velocity, roll, pitch, yaw, and the corresponding movements of the flyers controls on a continuous photo-strip. (2) Velometer : to indicate speed through the air of aëroplanes and airships. (3) Trajectograph : to record the path through the air of aëroplanes. (4) Air distance recorder or $\log$ : to give miles passed through the air of aircraft. (5) Recording accelerometer. (6) An airship and aëroplane instrument board complete. (7) Tautness meter: to enable the pull on a wire to be measured without altering or cutting it, or putting fixtures on the wire. Suitable for using during flight. Mr. J. D. Fry: A micromanometer capable of detecting differences of pressure of the order of one-millionth of a millimetre of mercury. The difference of pressure to be measured is applied to the two sides of a stretched membrane; the centre of the membrane by its displacement twists a mirror which is suspended in a special manner, the pressure differences being indicated by the deflection of a spot of light. National Physical Laboratory: Apparatus for the rapid determination of the lifting power of samples of hydrogen. (Mr. Guy Barr.) The method employed depends on the principle of balancing columns commonly used for comparing the densities of liquids. From the reading of a gauge, when the pressure difference is balanced, the lifting power of the hydrogen is determined with an accuracy of about 0.02 per cent. From the lifting power the purity of the hydrogen may be deduced by making corrections to N.T.P. after observation of the volume of a known mass of air.

The Cambridge Scientific Instrument Company, Limited: ( I) Apophorometer: an instrument designed by Prof. J. Joly, for easily obtaining sublimates from substances at high temperatures. (2) Rack barometer : a barometer of the marine type, in which a dial is substituted for the vernier in general use. The dial is divided to read directly in tenths of a millibar. (3) Stomatograph: an instrument which records the amount of opening of the stomata on a leaf. (4) Yaw indicator: this instrument is designed to indicate the direction of a current of gas in any plane. M. C. V. Boys : Rainbow cups-old and new patterns. The chief characteristic of the new pattern is the point support of the cup. The accurate work necessary with an axle is avoided and the friction is greatly reduced. The cup supported at a point is free to precess, and during this motion the coloured rings appear to expand and contract in time with the precession. The direction of precession is opposite to that of an ordinary top. Sir John Thornycroft: Model to illustrate the effect of a compound cross sea on vessels of various rolling periods. In the model a plane surface is supported on three points, two of which move vertically and the third is stationary. In the vertical motion of each of the two moving supports four simple harmonic motions are combined, and the phase of motion in the two differ by a quarter of their time period, and produce in the moving surface a symmetrical motion, resembling that of a small portion of a complicated sea in which similar waves are crossing at right angles. $M r . R$. E. Gillmor: The Sperry gyro compass. To be efficient the gyro compass must be so suspended that there is almost an entire absence of friction about the vertical axis, while at the same time forces must be impressed upon the wheel itself about the horizontal and vertical axis to cause the wheel to rotate into the plane of the earth's rotation. In the Sperry compass both are accomplished by suspending the gyroscopic or sensitive element from a stranded wire, the top of which is held in a frame surrounding the sensitive element and made to follow it by a system of electrical contacts controlling a motor which drives the frame.

Underfeed Stoker Company, Ltd.: $\mathrm{CO}_{2}$ thermoscope, a self-contained pocket instrument for the thermometric analysis of carbonic acid gas in furnace and other gases. The instrument operates by measuring the heat of reaction between $\mathrm{CO}_{2}$ and dry pulverised caustic alkali. (See Nature, April I7, p. I I I.) $M r . \quad F$. W. Jordan: Convection radiometer and thermo-galvanometer. This instrument is primarily intended for the measurement of feeble steady rates of evolution or absorption of heat. $M r$. Dugald Clerk: Determination of the volumetric heat of air, carbon dioxide, nitrogen, and flame in the cylinder of the internal-combustion engine. The volumetric heats of various gases and flames have been determined by the method of alternate compressions and expansions described in a paper read before the society in 1906. The present investigation deals with gases at low and high temperatures, and gives values between $100^{\circ} \mathrm{C}$. and $1000^{\circ} \mathrm{C}$. Laws of cooling have also been investigated, and the remarkable effect of turbulence on the rate of flame propagation in engines has been demonstrated. Prof. Leonard Hill: Kata-thermometers or comfort-meters. Two large-bulbed spirit thermometers are used. The bulb of one is surrounded with muslin. The stem of each is marked with heavy black lines at $110^{\circ} \mathrm{F}$., $100^{\circ} \mathrm{F}$, and $90^{\circ} \mathrm{F}$. Readings can be taken with the bulbs of the instruments (I) clothed; (2) exposed or shielded from radiant heat, e.g. a fire. By this means the heating and ventilation of rooms and the effect of clothes can be investigated and arranged so as to give (I) comfortable loss of body heat; (2) prevent depressing effect of uniformly heated air on cutaneous nerves. Prof. L. $R$. Wilberforce: Experiments with ripples. Ripples produced on a water surface by a vibrating dipper are projected by intermittent light so as to appear stroboscopically in slow motion. A phonic wheel drives the slotted disc which produces the intermittence, the motion being transmitted by fluid friction whereby a very uniform rotation is obtained.

$M r$. E. Leitz: Ultra-condenser for the observation of ultra-microscopic particles. The ultra-condenser has been devised for ultra-microscopic observ́ations, especially in the examination of fluids and gases. The condenser renders any ordinary microscope suitable for the purpose. It consists of two glass bodies, each having a reflecting spherical surface, cemented into a metal box fitted with a bayonet-jointed and rubberfaced coyer. The cover is fitted with a disc of quartz which serves as a cover glass. Underneath, the cover glass has a cavity for receiving the liquids and gases for examination. The condenser is not intended for high-power observations, and therefore objectives of shorter focal length than $8 \mathrm{~mm}$. may not be used. Prof. J. Norman Collie and Mr. H. S. Patterson: The presence of neon and helium in hydrogen after the passage of the electric discharge through the latter at low pressures. Whatever the explanation may be of the presence of neon and helium in hydrogen after the latter has sparked it seems to be certain that:(I) Neon and helium cannot be obtained from either glass or from the electrodes by heating alone; (2) glass, when heated to near its softening point and subjected to the action of kathode rays, is not permeable to neon or helium, so neither neon nor helium diffuses into the apparatus from the atmosphere. Mr. A. Fowler: New lines in the spectrum of hydrogen. Certain lines which occur in the spectra of stars and nebulæ have been attributed to hydrogen by Pickering and Rydberg in consequence of numerical 
relationships with the well-known Balmer series. Some of these "cosmic hydrogen" lines have lately been produced by passing a strong condenser discharge through a mixture of hydrogen and helium. Prof. H. H. Turner: Diagram of sun-spot analysis. Wolf's sun-spot numbers 1750-I910 can be closely represented by the harmonics of a period of 156 years, the coefficients of which rise and fall in a regular manner. The familiar $x I^{7}$ year period is the fourteenth harmonic, and has the maximum amplitude; but periods near it, especially thirteen and fifteen, are also important. All the chief harmonics were determined approximately, and their sum is compared with the numbers showing that the residuals are small. Capt. H. G. Lyons: An ancient Egyptian astronomical instrument. The original of this instrument was found in Upper Egypt, and is now in the Royal Museum at Berlin. By means of the wooden "sightvane," one observer aligned the plumb-line, which was held by a second observer, on the pole-star. The second observer then noted the passage of certain stars over the first observer's head, and thus determined the divisions of the night.

The National Physical Laboratory: Specimens illustrating the hehaviour of metals at relatively high temperatures. (Dr. Rosenhain and $M r$. Ewen.) In researches on the intercrystalline cohesion of metals their behaviour at temperatures near their respective melting points has been examined, both by heating in vacuo and by mechanical tests. The volatilisation which occurs in many metals at temperatures below their melting points results in the formation, on previously polished surfaces, of patterns corresponding to the structure of the metal. This constitutes a process of vacuum etching. Prof. W. J. Pope: A collection of artificial crystals. A number of large crystals of various salts prepared by slow crystallisation of aqueous solutions; most of the crystals are wellproportioned, and peculiarities of face development, \&c., can be observed upon them.

Prof. E. B. Poulton: All-female families and mixed families of Acraea encedon, bred by Mr. W. A. Lamborn in the Lagos district. These researches indicate the existence of two castes of females, one of which produces mixed families and the other all-female families. Both require fertilisation. $M r . L$. Doncaster: The moth Abraxas grossulariata: inheritance of tendency to produce unisexual broods. In six successive generations families consisting wholly of females have appeared. Dr. S. F. Harmer: Polyzoa of waterworks. (See Nature, May 8, p. 26o.) Dr. W. S. Bruce, Scottish Oceanographical Laboratory: Collection of deep-sea animals taken by the Scotia, Scottish National Antarctic Expedition, 1902, I903, and igo4. While a few of the animals shown are representative of shallow-water antarctic fauna, the greater number are from depths down to 2645 fathoms, or about three miles. An important feature of the scientific results of the Scotia lies in the fact that the Scottish expedition was the only antarctic expedition which has been completely fitted for deepsea research in high southern latitudes. Marine Biological Association of the United Kingdom: Living crabs and their allies arranged to show some of the various modifications of form and structure found in this group, and the relation between such modifications of structure and the mode of life of the animals. $M r$. Conrad Beck: Marine Coscinodiscus showing filaments, shown under the microscope with highpower dark ground illuminator (mounted by $H$. J. Waddington). The filaments radiating from these diatoms were discovered by Mr. Siddall of Chester, and some controversy has arisen as to whether they are protoplasmic, pseudopodia, or silicious spines. They are readily seen with a low power, but require very oblique dark ground illumination; as used for high powers, to demonstrate them. $M r . C$. $B$. Williams: British Protura. The Protura, first described by Silvester from Italy in I907, and first recorded from England last year by Mr. Bagnall, are a group of primitive Arthropods the systematic position of which has been the subject of much dis cussion. Their chief affinities are with the Insecta or with the Myriapoda, and they have been considered by various authorities as members of these groups and as a separate class intermediate between the two. Mr. H. G. Plimmer: Blood parasites: new, or from new hosts.

Dr. S. Watson: Skull, mandible, shoulder girdle, and forelimb of Dicynodon, sp. nov. female individual. Dr. D. H. Scott: Sections of Upper Devonian plants showing structure. Keeper of Geology, British Muse.m (Natural History): Remains of a Palæolithic human skull and mandible, with flint implements and mammalian teeth, from a gravel at Piltdown, Fletching, Sussex. This collection was made by Mr. Charles Dawson, and is described by Messrs. Dawson and A. Smith Woodward in the Quarterly Journal of the Geological Society for March, I9I3. The skull and mandible are regarded as representing a new genus and species of Hominidæ, named Eoanthropus daresoni. Prof. G. Elliot Smith: The brain-cast obtained from: the Piltdown skull, and other specimens for comparison. The cranial cast obtained from the Piltdown skull was shown alongside a series of specimens and drawings illustrating the form and constitution of the brain in primitive men, anthropoid apes, and other mammals supposed to be near the line of human ancestry. The objects of this comparative series are (I) to jllustrate and help in the interpretation of the distinctive features of the most primitive human brain to which we have access at present, and (2) to elucidate the nature of the evolutionary process by which the human brain has been derived from that of an early mammal. A specimen was shown representing an attempt at the restoration of the features of the Piltdown man's brain. Mr. Henry Balfour: Stone implements of Early Palæolithic types from South Africa. A selected series of stone implements from South Africa, exhibiting marked similarity in form and technique to the Chellian and Acheulian implements of the Lower Pleistocene river-gravels of England and western Europe. The implements exhibited were collected partly in the neighbourhood of Kimberley and partly on the Zambezi (Victoria Falls) and the Maramba River. Mr. C. Forster-Cooper: Remains of fossil mammals from the Early Miocene deposits of Dera Bugti in Baluchistan. The bone beds around Dera Bugti are interesting from the fact that they contain the earliest remains of mammals as yet discovered in the East. From their situation on the probable line of migration from or to Europe and Africa, it is hoped that interesting comparisons may be made with the earlier or contemporaneous faunas of Europe and Africa. Mr. H. Peake and Mr. E. A. Hooton: Skulls and grave furniture from Saxon graveyard at. East Shefford, Berks, explored 1912. This graveyard was discovered in $r 890$ during the construction of Lambourne Valley Railway. It was carefully explored in September, I012, when twenty-six graves were found. It seems to date from the early part of the sixth century. Prof. E. Hull: Coloured map of the North Atlantic and bordering regions to show the submerged terraces and river valleys as determined by the soundings of the Admiralty charts. 